\title{
Yttrium-90 radioembolization for advanced inoperable hepatocellular carcinoma
}

\author{
Victor Ho-Fun Lee ${ }^{1, *}$ \\ Dennis KC Leungl,* \\ Mai-Yee Luk' \\ Chi-Chung Tong' \\ Martin WM Law ${ }^{2}$ \\ Sherry CY $\mathrm{Ng}^{\prime}$ \\ Ka-Kin Wong ${ }^{3}$ \\ Ronnie TP Poon ${ }^{4}$ \\ Dora LW Kwong' \\ To-Wai Leung' \\ 'Department of Clinical Oncology, \\ Li Ka Shing Faculty of Medicine, The \\ University of Hong Kong, \\ 2Department of Nuclear Medicine, \\ ${ }^{3}$ Department of Radiology, \\ Queen Mary Hospital, ${ }^{4}$ Department \\ of Surgery, Li Ka Shing Faculty of \\ Medicine, The University of Hong \\ Kong, Hong Kong \\ *These authors contributed equally \\ to this work
}

\author{
This article was published in the following Dove Press journal: \\ OncoTargets and Therapy \\ 20 November 2015 \\ Number of times this article has been viewed
}

\begin{abstract}
Background: Advanced inoperable hepatocellular carcinoma (HCC) conferring a grave prognosis may benefit from yttrium-90 $\left({ }^{90} \mathrm{Y}\right)$ radioembolization.

Methods: Thirty patients with advanced inoperable HCC including those with any lesion $>8 \mathrm{~cm}$ in maximal diameter or multiple bi-lobar lesions (totally more than five lesions), or portal vein thrombosis treated with radioembolization were reviewed. Treatment efficacy and safety were evaluated. Univariate and multivariate analyses were performed for identifying potential prognostic factors.
\end{abstract}

Results: After a median follow-up of 18.3 months, the response rate was $30.0 \%$, and the disease control rate was $50.0 \%$. Median overall progression-free survival (PFS) and overall survival (OS) were 3.3 months and 13.2 months, respectively. Longer median PFS was noted in those who had transarterial chemoembolization before radioembolization ( 7.3 months vs 3.1 months; $P=0.021$ ) and duration of alfa-feto protein (AFP) response $\geq 6$ months ( 11.8 months vs 3.0 months; $P<0.001)$. Longer median OS was also revealed in those without portal vein thrombosis (17.1 months vs 4.4 months; $P=0.015$ ) and those whose duration of AFP response was $\geq 6$ months ( 21.2 months vs 8.6 months; $P=0.001)$. Seventeen patients $(56.7 \%)$ developed treatment-related complications including five (16.7\%) grade 3 events. Multivariate analysis revealed that treatment responders $(P=0.001)$ and duration of AFP response $\geq 6$ months $(P=0.006)$ were prognostic of PFS, whereas the absence of portal vein invasion $(P=0.025)$, treatment responders $(P=0.010)$, and duration of AFP response $\geq 6$ months $(P=0.001)$ were prognostic of OS.

Conclusion: ${ }^{90} \mathrm{Y}$ radioembolization is an alternative treatment with a promising outcome for poor-risk advanced inoperable HCC.

Keywords: radioembolization, transarterial chemoembolization, hepatocellular carcinoma, inoperable

\section{Introduction}

The overall prognosis of inoperable and unresectable hepatocellular carcinoma (HCC) is disappointing despite traditional and novel therapies including transarterial chemoembolization (TACE), systemic chemotherapy, palliative external-beam radiotherapy, or sorafenib. Patients whose tumors demonstrated portal vein thrombosis (present in $15 \%-40 \%$ of all HCCs) belong to, in particular, a poor prognostic group, and they are relatively contraindicated to TACE. ${ }^{1-4}$ Radioembolization with yttrium-90 $\left({ }^{90} \mathrm{Y}\right)$ microspheres has been increasingly employed for unresectable HCCs which are not amenable to liver transplantation, resection, or local ablative therapies like radiofrequency ablation (RFA) and percutaneous ethanol injection..$^{5-7}$ The microspheres labeled with ${ }^{90} \mathrm{Y}$ lodged preferentially into the microvasculature of the tributaries of tumorfeeding hepatic arteries, after careful and selective endovascular cannulation. They deliver high-energy (maximum $2.3 \mathrm{MeV}$ ) pure $\beta$-emitting fast electrons over a short
Correspondence: Victor Ho-Fun Lee Department of Clinical Oncology, I/F, Professorial Block, Queen Mary Hospital, 102 Pokfulam Road, Pokfulam, Hong Kong

Tel +85222554352

Fax +852 28726426

Email vhflee@hku.hk 
median depth of $2.4 \mathrm{~mm}$, thus minimizing radiation hazard to surrounding normal liver parenchyma. Previous studies revealed an improved median survival of 7-41.6 months in patients with intermediate-to-advanced HCC following radioembolization which produced a response rate between $20 \%$ and $77 \%$. $^{8,9}$ Radioembolization has also been found safe with promising results in those who had portal vein thrombosis. ${ }^{10-12}$ Besides, it was also found effective in patients who had hepatitis $B$ infection and in Asian patients who had a high incidence of hepatitis B-associated HCC. ${ }^{13,14}$ We reviewed the efficacy and safety of radioembolization in patients with advanced inoperable HCC, defined as either any inoperable lesion $>8 \mathrm{~cm}$ in maximal diameter or multiple bi-lobar lesions (totally more than five lesions) or portal vein thrombosis.

\section{Materials and methods}

\section{Patients}

This study was approved by the local institutional review board of the University of Hong Kong/Hospital Authority Hong Kong West Cluster, Hong Kong. This study was conducted in adherence with the guidelines of the Declaration of Helsinki. Patients with advanced HCC treated with radioembolization were reviewed. They were all treated with radioembolization with ${ }^{90} \mathrm{Y}$ resin microspheres (SIRspheres; SIRTEX Medical, Sydney, Australia) between January 2009 and December 2013 in Queen Mary Hospital, The University of Hong Kong, after a consensus was made in a multidisciplinary tumor board consisting of hepatobiliary surgeons, radiologists, and oncologists. Glass microspheres from TheraSphere ${ }^{\circledR}$ were not used as they have not yet been licensed in Hong Kong at the time of publication. After obtaining informed written consent from all of the participants, and reviewing baseline serum hematology, renal and liver biochemistry, alfa-feto protein (AFP) response, clotting profile, and image of the three-phase contrast-enhanced computed tomography (CT) scan of the liver, upper abdomen, and thorax, the patients underwent a planned hepatic angiography by interventional radiologists with specialization in radioembolization to delineate the course of hepatic arteries and identify any aberrant and collateral feeding vessels. Hyperselective cannulation of right or left hepatic artery followed by injection of technetium $99 \mathrm{~m}$ macroaggregated albumin ( ${ }^{99 \mathrm{~m}}$ Tc-MAA) and also subsequent ${ }^{90} \mathrm{Y}$ microspheres was performed for tumors situated mainly in a specific hepatic lobe after consensus by interventional radiologists, nuclear medicine physicians, medial physicists, and oncologists. Otherwise, both MAA and ${ }^{90} \mathrm{Y}$ microspheres were injected through the hepatic artery proper. If necessary, prophylactic embolization of gastroduodenal, gastric, and/or other extrahepatic arteries was performed to prevent undesirable delivery of microspheres into these vessels. Nuclear medicine physicians then injected ${ }^{99 m}$ Tc-MAA into the hepatic artery for the determination of ${ }^{99 \mathrm{~m}}$ Tc uptake by tumor and normal liver (so as to calculate the tumor-normal liver ratio) and percentage of lung shunting by single-photon emission CT/CT scan. Those who had tumor-normal liver ratio $<2.0$ or percentage of lung shunting $>20 \%$ were excluded from subsequent radioembolization to avoid suboptimal treatment outcomes and unfavorable toxicities. Prescription of activity of actual ${ }^{90} \mathrm{Y}$ microspheres was based on body surface area model as previously described. ${ }^{15}$ The final prescribed activity of ${ }^{90} \mathrm{Y}$ was determined by clinical oncologists and medical physicists, aiming at a radiation dose $>200$ Gy to the tumor and $<80$ Gy to the normal liver. Injection of ${ }^{90} \mathrm{Y}$ microspheres was performed by trained clinical oncologists 1-2 weeks after MAA injection. Postradioembolization Bremsstrahlung scan was done 4-6 hours after treatment to evaluate the uptake of ${ }^{90} \mathrm{Y}$ microspheres by the tumors. Patients were discharged the next day after overnight observation. Serial blood tests every month and CT scan of the liver, upper abdomen, and thorax were performed every 3 months after radioembolization for monitoring treatment efficacy and complications. Treatment response was determined by both European Association for the Study of Liver criteria and modified response evaluation criteria in solid tumors, as they were shown to better correlate with survival as compared with World Health Organization criteria. $^{16-18}$

\section{Statistical analysis}

Chi-square tests and Mann-Whitney $U$-tests were performed for comparison of discrete and continuous variables. Progression-free survival (PFS) was defined from the date of radioembolization to the date of radiological sign of progression or death from any cause, while overall survival (OS) was calculated from the date of radioembolization to the date of death from any cause. Duration of AFP response was calculated from the date of baseline AFP before radioembolization to the date when there were two consecutive elevations of AFP above nadir following radioembolization. Kaplan-Meier methods were used to calculate survivals. Log-rank tests and Cox proportional hazards model were used for comparison of survivals among subgroups. Univariate and multivariate analyses were performed for any prognostic factors of survival outcomes. Only covariates considered significant 
at $P$-value $<0.1$ in the univariable analysis were included in the multivariate model. Treatment-related toxicity was all graded with National Cancer Institute Common Terminology Criteria for Adverse Events version 4.0. ${ }^{19}$ Statistical significance was defined as $P<0.05$. All statistical analyses were carried out by Statistical Package for Social Sciences version 20.

\section{Results}

\section{Patient characteristics}

The characteristics of all patients are shown in Table 1. They all suffered from Barcelona Clinic Liver Cancer (BCLC) staging system either stage $\mathrm{B}$ or $\mathrm{C}$ diseases. ${ }^{20-22}$ Majorities had chronic hepatitis $B$ infection and received antiviral therapy for $>4$ years. Eighteen $(60.0 \%)$ had received prior therapy including TACE (15 patients, 50.0\%), RFA (four patients, 13.3\%), percutaneous ethanol injection (one patient, 3.3\%), high-intensity focused ultrasonography (HIFU) ablation (two patients, 6.7\%), and tumor resection (six patients, 20.0\%) and systemic treatment (three patients, 10.0\%). The median number of lesions was 8 (range 6-18). The median volume of tumors and normal liver was $258.9 \mathrm{~cm}^{3}\left(30.1-2,314.9 \mathrm{~cm}^{3}\right)$ and $1,124.2 \mathrm{~cm}^{3}\left(540.4-1,773.5 \mathrm{~cm}^{3}\right)$, respectively. Portal vein thrombosis was noted in 12 patients $(40.0 \%)$. The median prescribed dose was $1.4 \mathrm{GBq}$ (range 0.9-2.3 GBq). Prior

Table I Patient and tumor characteristics

\begin{tabular}{|c|c|c|c|c|}
\hline Patient and tumor characteristics & All (30 patients) & $\begin{array}{l}\text { Non-portal vein } \\
\text { thrombosis } \\
\text { (I } 8 \text { patients) }\end{array}$ & $\begin{array}{l}\text { Portal vein } \\
\text { thrombosis } \\
\text { (1 } 2 \text { patients) }\end{array}$ & P-value \\
\hline Median age, years (range) & $63(36-84)$ & $61(36-75)$ & $64(45-84)$ & 0.200 \\
\hline $\operatorname{Sex}(M / F)$ & $26 / 4$ & $15 / 3$ & II/I & 0.511 \\
\hline Body surface area, $\mathrm{m}^{2}$ (range) & $1.74(1.31-2.07)$ & $1.74(1.45-1.93)$ & $1.75(1.3 \mathrm{I}-2.07)$ & 0.518 \\
\hline Hepatitis B carrier & 21 (70.0\%) & $16(88.9 \%)$ & $5(4 \mid .7 \%)$ & 0.006 \\
\hline Hepatitis C carrier & $2(6.7 \%)$ & $0(0 \%)$ & $2(16.7 \%)$ & 0.073 \\
\hline Cirrhosis & $16(53.3 \%)$ & $8(44.4 \%)$ & $8(66.7 \%)$ & 0.232 \\
\hline Child-Pugh status & & & & 0.709 \\
\hline A & $24(80.0 \%)$ & I 4 (77.8\%) & 10 (83.3\%) & \\
\hline B & $6(20.0 \%)$ & $4(22.2 \%)$ & $2(16.7 \%)$ & \\
\hline \multicolumn{5}{|l|}{ BCLC stage } \\
\hline B & $18(60.0 \%)$ & 18 (100\%) & $0(0 \%)$ & $<0.001$ \\
\hline C & $12(40.0 \%)$ & $0(0 \%)$ & $12(100 \%)$ & \\
\hline Median number of lesions (range) & $8(6-18)$ & $7(6-18)$ & $8(6-15)$ & 0.582 \\
\hline Portal vein thrombosis & $12(40.0 \%)$ & $\mathrm{N} / \mathrm{A}$ & $12(100 \%)$ & N/A \\
\hline Main & $8(26.7 \%)$ & N/A & $8(66.7 \%)$ & \\
\hline Left only & I (3.3\%) & $\mathrm{N} / \mathrm{A}$ & I (8.3\%) & \\
\hline Right only & $3(10.0 \%)$ & $\mathrm{N} / \mathrm{A}$ & $3(25.0 \%)$ & \\
\hline Prior TACE & I5 (50.0\%) & II (6I.I\%) & $4(33.3 \%)$ & 0.136 \\
\hline Prior RFA & $4(13.3 \%)$ & $2(1 \mathrm{l} .1 \%)$ & $2(16.7 \%)$ & 0.661 \\
\hline Prior PEl & I (3.3\%) & $0(0 \%)$ & I (8.3\%) & 0.213 \\
\hline Prior HIFU ablation & $2(6.7 \%)$ & $2(1 \mathrm{I} .1 \%)$ & $0(0 \%)$ & 0.232 \\
\hline Prior tumor resection & $6(20.0 \%)$ & $5(27.8 \%)$ & I (8.3\%) & 0.192 \\
\hline Prior systemic therapy & $3(10.0 \%)$ & $2(1 \mathrm{I} .1 \%)$ & I (8.3\%) & 0.804 \\
\hline Median AFP at baseline (ng/mL) (range) & $31(12-17,610)$ & $406(12-10,389)$ & $221(18-17,160)$ & 0.232 \\
\hline Median volume of tumor $\left(\mathrm{cm}^{3}\right)$ (range) & $258.9(30.1-2,3 \mid 4.9)$ & $254.1(36.2-2,3 \mid 4.9)$ & $307.2(30.1-894.5)$ & 0.755 \\
\hline Median volume of normal liver $\left(\mathrm{cm}^{3}\right)$ (range) & $\mathrm{I}, \mathrm{I} 24.2(540.4-\mathrm{I}, 773.5)$ & $\mathrm{I}, 080.6(631.0-1,644.9)$ & $\mathrm{I}, 2 \mathrm{I} 0.0(540.4-\mathrm{I}, 773.5)$ & 0.346 \\
\hline Median tumor/normal liver ratio (range) & $3.9(2.1-13.5)$ & $3.9(2.1-11.0)$ & $4.1(2.2-13.5)$ & 0.982 \\
\hline Median lung shunting (\%) (range) & $6.7(3.2-17.3)$ & $6.9(4.1-17.3)$ & $6.7(3.2-\mid I .0)$ & 0.325 \\
\hline Artery embolization before radioembolization & $4(13.3 \%)$ & $4(22.2 \%)$ & $0(0 \%)$ & 0.079 \\
\hline Median prescribed dose (GBq) (range) & $1.4(0.9-2.3)$ & I.5 (0.9-I.7) & $1.39(0.9-2.3)$ & 0.755 \\
\hline Median dose to tumor (range) (Gy) & $233.0(159.0-692.0)$ & $230.0(163.0-528.0)$ & $241.0(159.0-692.0)$ & 0.517 \\
\hline Median dose to liver (range) (Gy) & $61.0(34.0-83.0)$ & $59.5(44.0-83.0)$ & $66.0(34.0-80.0)$ & 0.912 \\
\hline Artery into which microspheres were injected & & & & 0.519 \\
\hline Hepatic artery proper & $7(23.3 \%)$ & $3(16.7 \%)$ & $4(33.3 \%)$ & \\
\hline Right hepatic artery & $19(63.4 \%)$ & $12(66.6 \%)$ & $7(58.4 \%)$ & \\
\hline Left hepatic artery & $4(13.3 \%)$ & $3(16.7 \%)$ & I (8.3\%) & \\
\hline
\end{tabular}

Abbreviations: AFP, alfa-feto protein; BCLC, Barcelona Clinic Liver Cancer; HIFU, high-intensity focused ultrasonography; N/A, not applicable; PEI, percutaneous ethanol injection; RFA, radiofrequency ablation; TACE, transarterial chemoembolization. 
embolization of gastroduodenal artery was necessary in four patients $(13.3 \%)$ before injection of ${ }^{90} \mathrm{Y}$ microspheres to minimize radiation-induced gastroduodenitis and its complications.

Nine patients $(30.0 \%)$ had local response including one patient with complete response lasting for 8 months, and an additional six patients $(20.0 \%)$ had stable disease, resulting in a disease control rate of $50.0 \%$. Response rate was lower in patients with portal vein thrombosis (16.7\%) compared with those without thrombosis (38.9\%), but this was statistically insignificant $(P=0.193)$. The median PFS was 3.3 months, and the median OS was 13.2 months. Subgroup analysis revealed that those who received prior TACE before radioembolization enjoyed longer PFS
(7.3 months) than those who did not (3.1 months; $P=0.021$ ) (Figure 1). In addition, those who had duration of AFP response $\geq 6$ months after radioembolization exhibited longer PFS (11.8 months) than those whose AFP response was $<6$ months after radioembolization (3.0 months; $P<0.001$ ) (Figure 1). Treatment responders (including complete and partial response) were also found to have longer PFS (11.8 months vs 3.1 months; $P<0.001$ ). Those without portal vein thrombosis had borderline longer PFS (4.5 months) than those whose tumor exhibited portal vein thrombosis (3.0 months; $P=0.072$ ). Upon progression to radioembolization, 15 patients $(50.0 \%)$ received further treatment including TACE (eight patients, $26.7 \%$ ), RFA (four patients, 13.3\%), HIFU (one patient, 3.3\%),
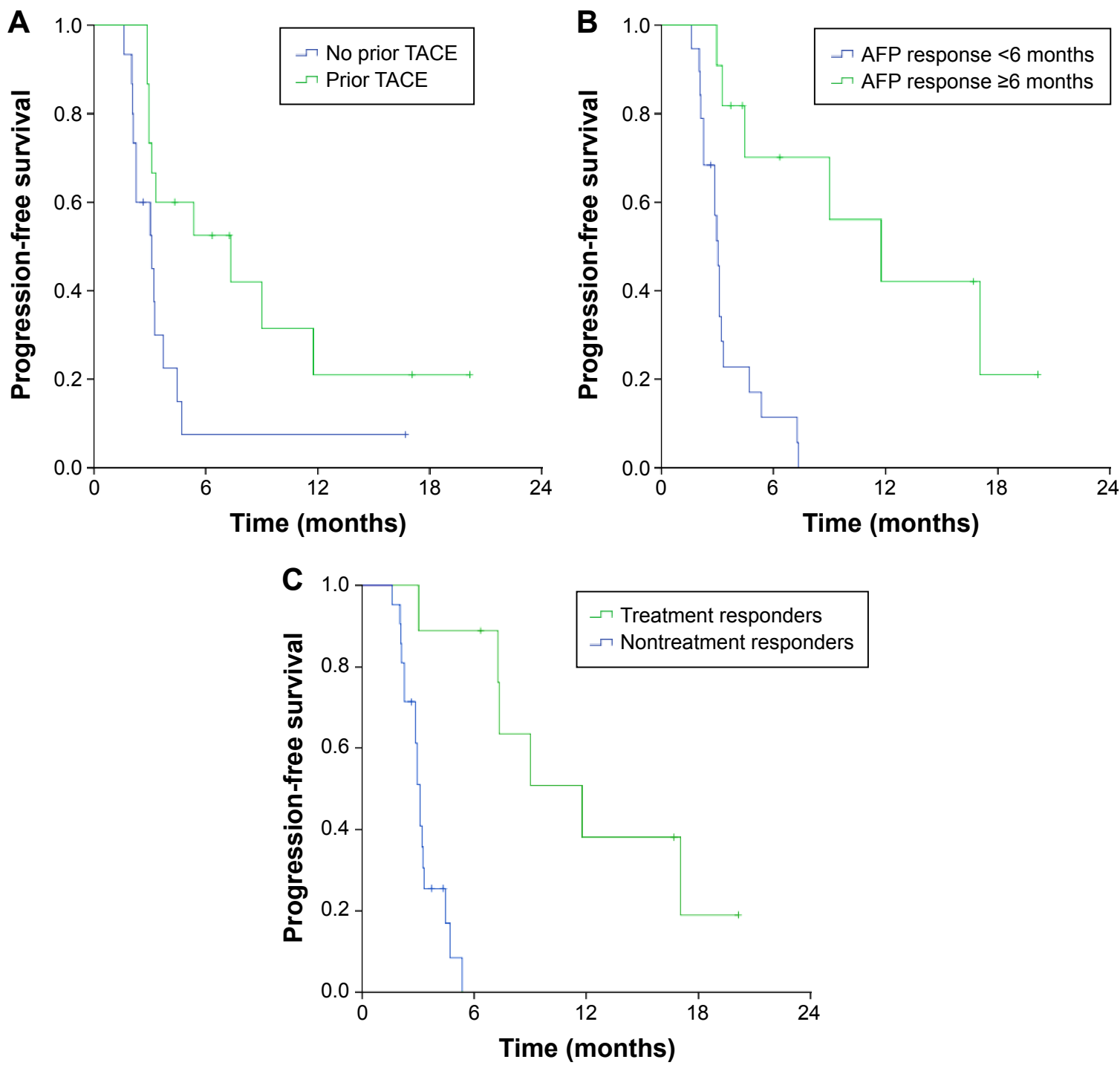

Figure I Progression-free survival of patients (A) with or without prior TACE before radioembolization, and (B) those who had duration of AFP response $\geq 6$ months or $<6$ months and (C) treatment response after radioembolization.

Abbreviations: AFP, alfa-feto protein; TACE, transarterial chemoembolization. 
metastasectomy (two patients, 6.7\%), and other locoregional therapy (two patients, 6.7\%) and systemic therapy with sorafenib and chemotherapy (seven patients, 23.3\%). Longer median OS was seen in those without portal vein thrombosis (17.1 months vs 4.4 months; $P=0.015$ ) and those whose AFP duration was $\geq 6$ months after radioembolization (21.2 months vs 8.6 months; $P=0.001$ ) compared to their counterparts (Figure 2). More importantly, treatment responders definitely derived longer median OS (21.2 months vs 8.6 months; $P=0.015)$ than nonresponders.

A

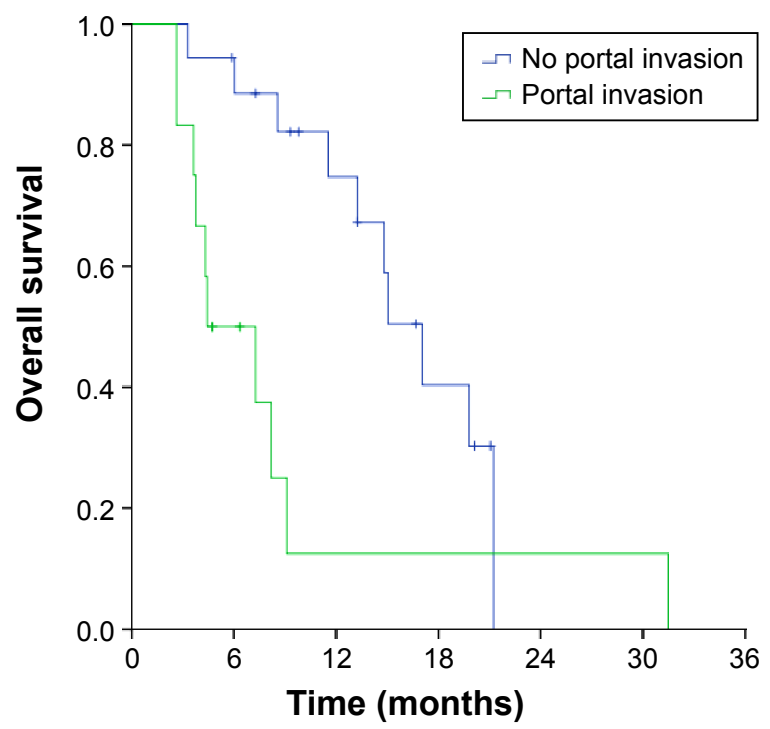

\section{Univariate and multivariate analysis}

Univariate and multivariate analyses were performed for predictors of PFS and OS (Table 2). Univariate analysis revealed that prior TACE $(P=0.046)$, tumor volume $(P=0.045)$, treatment responders $(P=0.003)$, and duration of AFP response $\geq 6$ months $(P=0.001)$ were prognostic of PFS, while portal vein thrombosis $(P=0.020)$, treatment responders $(P=0.024)$, and duration of AFP response $\geq 6$ months $(P=0.005)$ were prognostic factors of OS. In multivariate analysis, treatment responders $(P=0.001)$ and duration of AFP response $\geq 6$ months

B

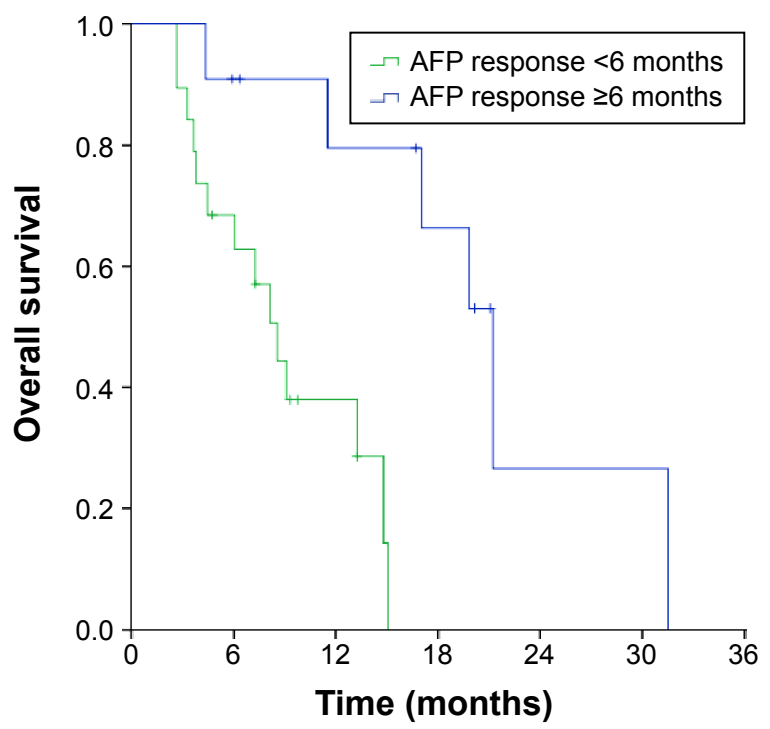

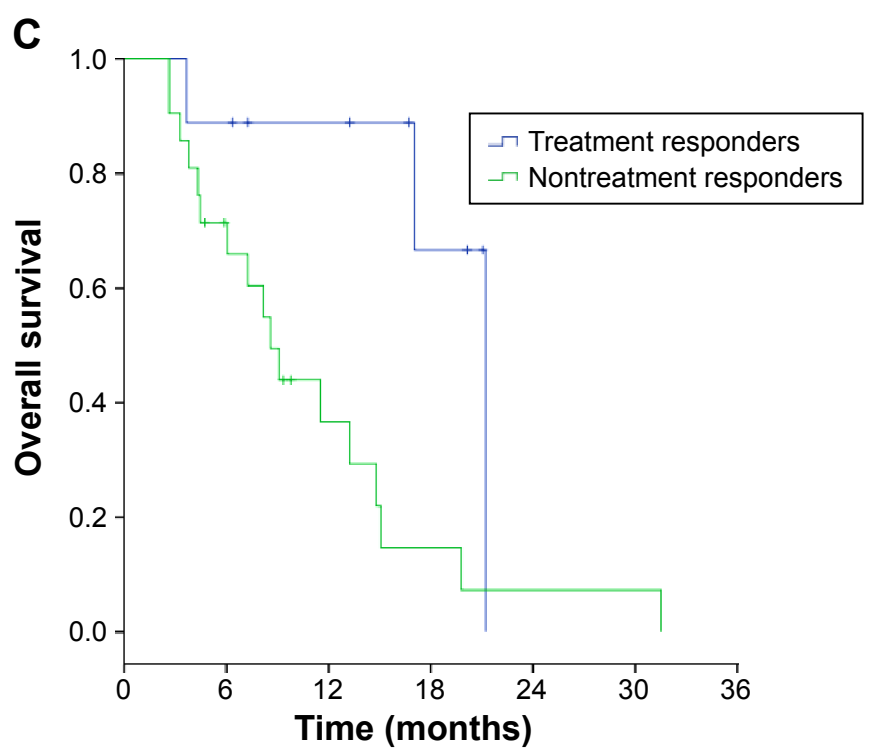

Figure 2 Overall survival of patients (A) with or without portal vein thrombosis, and (B) those who had duration of AFP response $\geq 6$ months or $<6$ months and (C) treatment response after radioembolization.

Abbreviation: AFP, alfa-feto protein. 
Table 2 Association of clinicopathological parameters with survival outcomes in univariate and multivariate analyses

\begin{tabular}{|c|c|c|c|c|c|c|c|c|}
\hline \multirow[t]{3}{*}{ Parameter } & \multicolumn{4}{|c|}{ Univariate analysis } & \multicolumn{4}{|c|}{ Multivariate analysis } \\
\hline & \multicolumn{2}{|l|}{ PFS } & \multicolumn{2}{|l|}{ OS } & \multicolumn{2}{|l|}{ PFS } & \multicolumn{2}{|l|}{ OS } \\
\hline & $\begin{array}{l}\text { Hazard ratio } \\
(95 \% \mathrm{Cl})\end{array}$ & $P$-value & $\begin{array}{l}\text { Hazard ratio } \\
(95 \% \mathrm{Cl})\end{array}$ & $P$-value & $\begin{array}{l}\text { Hazard ratio } \\
(95 \% \mathrm{Cl})\end{array}$ & $P$-value & $\begin{array}{l}\text { Hazard ratio } \\
(95 \% \mathrm{Cl})\end{array}$ & $P$-value \\
\hline Prior TACE & $\begin{array}{l}0.404 \\
(0.166-0.984)\end{array}$ & 0.046 & $\begin{array}{l}0.407 \\
(0.160-1.038)\end{array}$ & 0.060 & $\begin{array}{l}0.543 \\
(0.211-1.202)\end{array}$ & 0.122 & $\begin{array}{l}0.480 \\
(0.205-1.247)\end{array}$ & 0.135 \\
\hline $\begin{array}{l}\text { Portal vein } \\
\text { thrombosis }\end{array}$ & $\begin{array}{l}0.444 \\
(0.178-1.11 I)\end{array}$ & 0.083 & $\begin{array}{l}0.322 \\
(0.124-0.836)\end{array}$ & 0.020 & $\begin{array}{l}0.567 \\
(0.208-\mid .22 I)\end{array}$ & 0.131 & $\begin{array}{l}0.310 \\
(0.112-0.859)\end{array}$ & 0.025 \\
\hline Tumor volume & $\begin{array}{l}2.200 \\
(1.018-4.756)\end{array}$ & 0.045 & $\begin{array}{l}1.407 \\
(0.650-3.043)\end{array}$ & 0.386 & $\begin{array}{l}2.187 \\
(0.879-4.80 I)\end{array}$ & 0.129 & ND & ND \\
\hline $\begin{array}{l}\text { Treatment } \\
\text { responders }\end{array}$ & $\begin{array}{l}0.043 \\
(0.005-0.350)\end{array}$ & 0.003 & $\begin{array}{l}0.235 \\
(0.067-0.827)\end{array}$ & 0.024 & $\begin{array}{l}0.079 \\
(0.010-0.636)\end{array}$ & 0.001 & $\begin{array}{l}0.235 \\
(0.067-0.827)\end{array}$ & 0.010 \\
\hline $\begin{array}{l}\text { Duration of AFP } \\
\text { response } \geq 6 \text { months }\end{array}$ & $\begin{array}{l}0.124 \\
(0.036-0.433)\end{array}$ & 0.001 & $\begin{array}{l}0.111 \\
(0.023-0.523)\end{array}$ & 0.005 & $\begin{array}{l}0.205 \\
(0.056-0.749)\end{array}$ & 0.006 & $\begin{array}{l}0.104 \\
(0.021-0.513)\end{array}$ & 0.001 \\
\hline
\end{tabular}

Note: Only variables found significant in univariate analysis $(P<0.1)$ were considered in multivariate analysis.

Abbreviations: AFP, alfa-feto protein; $\mathrm{Cl}$, confidence interval; ND, not done; OS, overall survival; PFS, progression-free survival; TACE, transarterial chemoembolization.

$(P=0.006)$ were prognostic of PFS, whereas portal vein thrombosis $(P=0.025)$, treatment responders $(P=0.010)$, and duration of AFP response $\geq 6$ months $(P=0.001)$ were prognostic of OS.

\section{Safety profiles}

Complications developed in 17 patients (56.7\%), among which grade 3 events were noted in five patients (16.7\%) after radioembolization as shown in Table 3. Four patients (13.3\%) developed gastric and duodenal ulcers, and microspheres were identified under microscopy in gastric and duodenal biopsies. Three patients had their ulcers improved after use of proton pump inhibitors and symptomatic care except one who eventually received gastrectomy despite prior prophylactic embolization of gastroduodenal artery before radioembolization. Another patient developed selflimiting cholecystitis which was most probably attributed to incidental spilling of microspheres into his cystic artery. All grade 3 or above gastrointestinal complications developed

Table 3 Radioembolization-related toxicities

\begin{tabular}{lll}
\hline Toxicities & All grades (\%) & Grade $\mathbf{3}$ events (\%) \\
\hline Nausea & $4(13.3)$ & $\mathrm{I}(3.3)$ \\
Vomiting & $5(16.7)$ & $\mathrm{I}(3.3)$ \\
Anorexia & $6(20.0)$ & $0(0)$ \\
Malaise & $2(6.7)$ & $\mathrm{I}(3.3)$ \\
Fever & $4(13.3)$ & $2(6.7)$ \\
Abdominal pain & $8(26.7)$ & $0(0)$ \\
Anemia & $\mathrm{I}(3.3)$ & $\mathrm{I}(3.3)$ \\
Anorexia & $5(20.0)$ & $0(0)$ \\
Peptic/duodenal ulcers & $4(13.3)$ & $2(6.7)$ \\
Cholecystitis & $\mathrm{I}(3.3)$ & $0(0)$ \\
Impaired liver function & $3(10.0)$ & $0(0)$ \\
\hline
\end{tabular}

Note: Grading of toxicities was based on Common Terminology Criteria for Adverse Events version 4.0. in the first eight patients at the time when all interventional radiologists and oncologists were still gaining experience, and there were no such complications afterward. No grade $\geq 4$ complications or treatment-related mortality occurred.

\section{Discussion}

HCC is a common cancer worldwide which claims 700,000 lives every year. ${ }^{23}$ The incidence is highest in Asian and African countries secondary to the high incidence of chronic hepatitis B infection. TACE has been the standard treatment for unresectable HCC for more than two decades. ${ }^{24-26}$ However, it is relatively contraindicated in those whose tumor harbored portal vein thrombosis, which is present in $10 \%-40 \%$ of patients at the time of diagnosis. ${ }^{3,27,28} \mathrm{TACE}$ is associated with an increased risk of ischemia and necrosis of the remaining normal liver parenchyma and treatment-related mortality in those having portal vein thrombosis in their tumors. ${ }^{29}$ Thus, only very limited treatment options including systemic therapy and best supportive care were available. Radioembolization with ${ }^{90} \mathrm{Y}$ microspheres is increasingly gaining popularity as first-line treatment or subsequent therapy after failure to prior locoregional therapy for unresectable HCC. Accumulating evidence has proven its efficacy and prolongation of survival in patients with intermediateto-advanced HCC. Tumor cell death is mainly contributed by local short-distance irradiation by ${ }^{90} \mathrm{Y}$ microspheres rather than embolization. In fact, an oxygenated microenvironment with free radical generation enhances more radiation-induced tumor cell death..$^{30}$ Treatment responders definitely enjoyed a longer PFS and OS in our study, essentially comparable with the long-term results of a previously reported prospective 
single-center study by Salem et al. ${ }^{9}$ On top of that, we were able to show that AFP response $\geq 6$ months after radioembolization was translated into a lengthened PFS and OS. Our current study also echoed with other previous studies that radioembolization could bring some benefits and efficacy to those who had portal vein thrombosis in their HCC, albeit a shorter PFS and OS as compared to those without portal vein thrombosis. Our results agreed with those in previous studies that portal vein thrombosis is an unfavorable prognostic group even after radioembolization. ${ }^{30}$ Salem et al reported median survival of 7.7 months and 4.5 months, respectively, after radioembolization in patients with Child-Pugh Class A and B status and main portal vein thrombosis. ${ }^{9}$ A median survival between 3.2 months and 10 months was observed in those with portal vein thrombosis as compared to 15.3-16.4 months in those without portal vein thrombosis in another four studies. ${ }^{12,31,32}$ Patients who had branched first-order portal vein thrombosis survived longer (6.5-16.6 months) than those who had main portal vein thrombosis (4.4-7.5 months). ${ }^{33,34}$ More recently, Kokabi et al demonstrated that Eastern Cooperative Oncology Group performance status of 0 , Child-Pugh Class A, and lung shunting fraction $<10 \%$ were independent prognostic factors of time to progression after radioembolization in patients who had portal vein thrombosis in their HCC. ${ }^{35}$

Since treatment for patients with portal vein thrombosis is essentially palliative, it is crucial to offer them effective treatment with minimal toxicity. Targeted therapy with sorafenib is another treatment option, but there was only a modest improvement in survival. ${ }^{36,37}$ Recently, Hong Kong has devised and published a new Hong Kong Liver Cancer Staging System with treatment stratification for patients with HCC..$^{38}$ It was proven more superior to BCLC system in prognosticating the survival outcomes of patients with HCC. However, it did not include patients treated with external radiotherapy or radioembolization as the cohort included those diagnosed between 1995 and 2008. The patients in our current study belonged to those classified as between stage IIIb and IVb diseases under this new Hong Kong staging system and enjoyed a longer survival than their counterparts in this large cohort (median OS between 2.13 months and 6.01 months). With the incorporation of radioembolization as part of the management protocol for these poor-risk groups, their survival would definitely be further improved.

Toxicity profiles in our study were also comparable to other reported studies..$^{39,40}$ One patient developed grade 3 peptic ulcer despite prior embolization of gastroduodenal artery and eventually gastrectomy was carried out for persistent bleeding ulcer and anemia. Radiation-related peptic and duodenal ulcers were well recognized side effects in $\sim 10 \%$ of patients due to the inadvertent delivery of microspheres to the gastroduodenal artery and less commonly short gastric arteries. It is sometimes quite long lasting and troublesome to patients, which is refractory to supportive treatment and proton pump inhibitors. Learning from experience may also be important as we encountered no more patients who suffered from this gastrointestinal complication after radioembolization from the ninth patient onward. Meticulous and slow injection of microspheres may reduce the chance of backflow to the gastroduodenal artery and other small arteries supplying the stomach and duodenum. Prophylactic embolization and prophylactic use of proton pump inhibitors may also be helpful.

As a conclusion, our study demonstrated the feasibility and efficacy of radioembolization in patients with advanced inoperable HCC with a modest improvement in survival. It may provide an alternative treatment option for this poor prognostic group.

\section{Disclosure}

The authors report no conflicts of interest in this work.

\section{References}

1. Trevisani F, D'Intino PE, Caraceni $\mathrm{P}$, et al. Etiologic factors and clinical presentation of hepatocellular carcinoma. Differences between cirrhotic and noncirrhotic Italian patients. Cancer. 1995;7:2220-2232.

2. Calvet X, Bruix J, Ginés P, et al. Prognostic factors of hepatocellular carcinoma in the west: a multivariate analysis in 206 patients. Hepatology. 1990; $12: 753-760$

3. Llovet JM, Bustamante J, Castells A, et al. Natural history of untreated nonsurgical hepatocellular carcinoma: rationale for the design and evaluation of therapeutic trials. Hepatology. 1999;29:62-67.

4. Bruix J, Sherman M; Practice Guidelines Committee, American Association for the Study of Liver Diseases. Management of hepatocellular carcinoma. Hepatology. 2005;42:1208-1236.

5. Liapi E, Geschwind JF. Intra-arterial therapies for hepatocellular carcinoma: where do we stand? Ann Surg Oncol. 2010;17: 1234-1246.

6. Kennedy A, Nag S, Salem R, et al. Recommendations for radioembolization of hepatic malignancies using yttrium-90 microsphere brachytherapy: a consensus panel report from the Radioembolization Brachytherapy Oncology Consortium (REBOC). Int J Radiat Oncol Biol Phys. 2007;68:13-23.

7. Sacco R, Mismas V, Marceglia S, et al. Transarterial radioembolization for hepatocellular carcinoma: an update and perspectives Wolrd J Gastroenterol. 2015;21:6518-6525.

8. Sangro B, Salem R, Kennedy A, Coldwell D, Wasan H. Radioembolization for hepatocellular carcinoma: a review of the evidence and treatment recommendations. Am J Clin Oncol. 2011;34:422-431.

9. Salem R, Lewandowski RJ, Mulcahy MF, et al. Radioembolization for hepatocellular carcinoma using yttrium-90 microspheres: a comprehensive report of long-term outcomes. Gastroenterology. 2010; 138:52-64. 
10. Salem R, Lewandowski R, Roberts C, et al. Use of Yttrium-90 glass microspheres (TheraSphere) for the treatment of unresectable hepatocellular carcinoma in patients with portal vein thrombosis. $J$ Vasc Interv Radiol. 2004;15:335-345.

11. Sangro B, Bilbao JI, Boan J, et al. Radioembolization using 90Y-resin microspheres for patients with advanced hepatocellular carcinoma. Int J Radiat Oncol Biol Phys. 2006;66:792-800.

12. Iñarrairaegui $\mathrm{M}$, Thurston $\mathrm{KG}$, Bilbao JI, et al. Radioembolization with use of yttrium-90 resin microspheres in patietns with hepatocellular carcinoma and portal vein thrombosis. J Vasc Interv Radiol. 2010; 21:1205-1212.

13. Biederman DM, Titano JJ, Lee KM, et al. Yttrium-90 glass-based microsphere radioembolization in the treatment of hepatocellular carcinoma secondary to the hepatitis B virus: safety, efficacy, and survival. J Vasc Interv Radiol. Epub 2015 Aug 25.

14. Khor AY, Toh Y, Allen JC, et al. Survival and pattern of tumor progression with yttrium-90 microsphere radioembolization in predominantly hepatitis B Asian patients with hepatocellular carcinoma. Hepatol Int. 2014;8(3):395-404.

15. Salem R, Thurston KG. Radioembolization with ${ }^{90}$ yttrium microspheres: a state-of-the-art brachytherapy treatment for primary and secondary liver malignancies. Part 1: technical and methodologic considerations. J Vasc Interv Radiol. 2006;17:1251-1278.

16. Bruix J, Sherman M, Llovet JM, et al. Clinical management of hepatocellular carcinoma. Conclusions of the Barcelona-2000 EASL Conference. European Association for the Study of the Liver. J Hepatol. 2001;35:421-430.

17. Lencioni R, Llovet JM. Modified RECIST (mRECIST) assessment for hepatocellular carcinoma. Semin Liver Dis. 2010;30:52-60.

18. Prajapati HJ, Spivey JR, Hanish SI, et al. mRECIST and EASL responses at early time point by contrast-enhanced dynamic MRI predict survival in patients with unresectable hepatocellular carcinoma (HCC) treated with doxorubicin drug-eluting beads transarterial chemoembolization (DEB TACE). Ann Oncol. 2013;24:965-973.

19. Common Terminology Criteria for Adverse Events (CTCAE), Version 4.0. Available from: http://evs.nci.nih.gov/ftp1/CTCAE/CTCAE_ 4.03_2010-06-14_QuickReference_5x7.pdf. Accessed January 30, 2014.

20. Llovet JM, Brú C, Bruix J. Prognosis of hepatocellular carcinoma: the BCLC staging classification. Semin Liver Dis. 1999;19:329-338.

21. Cillo U, Vitale A, Grigoletto F, et al. Prospective validation of the Barcelona clinic liver cancer staging system. J Hepatol. 2006;44:723-731.

22. Grieco A, Pompili M, Caminiti G, et al. Prognoistic factors for survival in patients with early-intermediate hepatocellular carcinoma undergoing non-surgical therapy: comparison of Okuda, CLIP and BCLC staging systems in a single Italian centre. Gut. 2005;54:411-418.

23. Yang JD, Roberts LR. Hepatocellular carcinoma: a global view. Nat Rev Gastroenterol Hepatol. 2010;7:448-458.

24. Llovet JM, Real MI, Montaña X, et al; Barcelona Liver Cancer Group. Arterial embolization or chemoembolization versus symptomatic treatment in patients with unresectable hepatocellular carcinoma: a randomized controlled trial. Lancet. 2002;359:1734-1739.

25. Lo CM, Ngan H, Tso WK, et al. Randomized controlled trial of transarterial lipiodol chemoembolization for unresectable hepatocellular carcinoma. Hepatology. 2002;35:1164-1171.

OncoTargets and Therapy

\section{Publish your work in this journal}

OncoTargets and Therapy is an international, peer-reviewed, open access journal focusing on the pathological basis of all cancers, potential targets for therapy and treatment protocols employed to improve the management of cancer patients. The journal also focuses on the impact of management programs and new therapeutic agents and protocols on
26. Llovet JM, Bruix J. Systematic review of randomized trials for unresectable hepatocellular carcinoma: chemoembolization improves survival. Hepatology. 2003;37:429-442.

27. Minagawa M, Makuuchi M. Treatment of hepatocellular carcinoma accompanied by portal vein tumor thrombus. World $J$ Gastroenterol. 2006;12:7561-7567.

28. Lau WY, Sangro B, Chen PJ, et al. Treatment for hepatocellular carcinoma with portal vein tumor thrombosis: the emerging role for radioembolization using yttrium-90. Oncology. 2013;84:311-318.

29. Bruix J, Sherman M. AASLD Practice Guideline: Management of Hepatocellular Carcinoma: An Update; 2010. Available from: http://www. aasld.org/sites/default/files/guideline_documents/HCCUpdate2010.pdf. Accessed May 8, 2014.

30. Sangro B, Carpanese L, Cianni R, et al; European Network on Radioembolization with Yttrium-90 Resin Microspheres (ENRY). Survival after yttrium-90 resin microsphere radioembolization of hepatocellular carcinoma across Barcelona Clinic Liver Cancer Stages: a European evaluation. Hepatology. 2011;54:868-878.

31. Hilgard P, Hamami M, Fouly AE, et al. Radioembolization with yttrium- 90 glass microspheres in hepatocellular carcinoma: European experience on safety and long-term survival. Hepatology. 2010;52:1741-1749.

32. Woodall CE, Scoggins CR, Ellis SF, et al. Is selective internal radioembolization safe and effective for patients with inoperable hepatocellular carcinoma and venous thrombosis? J Am Coll Surg. 2009;208:375-382.

33. Tsai AL, Burke CT, Kennedy AS, et al. Use of yttrium- 90 microspheres in patients with advanced hepatocellular carcinoma and portal vein thrombosis. J Vasc Interv Radiol. 2010;21:1377-1384.

34. Kulik LM, Carr BI, Mulcahy MF, et al. Safety and efficacy of 90Y radiotherapy for hepatocellular carcinoma with and without portal vein thrombosis. Hepatology. 2008;47:71-81.

35. Kokabi N, Camacho JC, Xing M, et al. Open-label prospective study of the safety and efficacy of glass-based yttrium 90 radioembolization for infiltrative hepatocellular carcinoma with portal vein thrombosis. Cancer. Epub 2015 Apr 6.

36. Llovet JM, Ricci S, Mazzaferro V, et al; SHARP Investigators Study Group. Sorafenib in advanced hepatocellular carcinoma. NEngl J Med. 2008;359:378-390.

37. Cheng AL, Kang YK, Chen Z, et al. Efficacy and safety of sorafenib in patients in the Asia-Pacific region with advanced hepatocellular carcinoma: a phase III randomised, double-blind, placebo-controlled trial. Lancet Oncol. 2009;10:25-34.

38. Yau T, Tang VY, Yao JT, Fan ST, Lo CM, Poon RT. Development of Hong Kong liver cancer staging system with treatment stratification for patients with hepatocellular carcinoma. Gastroenterology. 2014;146: 1691-1700.

39. Stubbs RS, Cannan RJ, Mitchell AW. Selective internal radiation therapy with 90yttrium microspheres for extensive colorectal liver metastases. J Gastrointest Surg. 2001;5:294-302.

40. Lim L, Gibbs P, Yip D, et al. A prospective evaluation of treatment with selective internal radiation therapy (SIR-spheres) in patients with unresectable liver metastases from colorectal cancer previously treated with 5-FU based chemotherapy. BMC Cancer. 2005;5:132.

\section{Dovepress}

patient perspectives such as quality of life, adherence and satisfaction The manuscript management system is completely online and includes a very quick and fair peer-review system, which is all easy to use. Visit http://www.dovepress.com/testimonials.php to read real quotes from published authors. 